This document is published in:

International Journal of Industrial Organization (1999), 17(1), 25-57. DOI: 10.1016/S0167-7187(97)00020-9

(C) 1999 Elsevier Science B.V. 


\title{
An empirical oligopoly model of a regulated market
}

\author{
$\mathrm{M}^{\mathrm{a}}$ Consuelo Pazó ${ }^{\mathrm{a}, *}$, Jordi Jaumandreu ${ }^{\mathrm{b}}$ \\ ${ }^{\mathrm{a}}$ Universidad de Vigo, Facultad de CC. EE., Ap. 874, 36200 Vigo, Spain \\ ${ }^{\mathrm{b}}$ Fundación Empresa Pública, Pza. Marqués de Salamanca 8, 28006 Madrid, Spain
}

\begin{abstract}
We model a three fir o ligopoly ( the S panish f ertilizer i ndustry from 1976 to 1988) which was subject to price regulation in the form of price ceilings. A theoretical and econometric model is developed in order to identify simultaneously the behaviour of the firm and the degree to which regulation constrained the price. The collusive market-sharing arrangements involving asymmetric firms and the less collusive outcomes of Cournot and Stackelberg, together with their constrained counterparts, are considered as particular behavioural hypotheses. The estimation of an aggregated and a disaggregated version of the model, by General Method of Moments techniques, leads us to identify the regulationconstrained Stackelberg equilibrium as the most likely outcome given the observed data.
\end{abstract}

Keywords: Oligopoly; Price regulation; Market-sharing arrangements; Cournot; Stackelberg JEL classificatio : L13; L51; L65

\section{Introduction}

Since the Bresnahan (1989) survey, the number of empirical studies of industries with market power has been increasing. All such studies have in common the use of a structural econometric approach and progress in the area has been made by using individual data from firms by examining a richer set of possible outcomes, and by refinin the methods used to test the behavioural hypotheses. Recent examples of this type of work are Gasmi et al. (1992); Berndt et al. (1990).

\footnotetext{
*Corresponding author; e-mail: cpazo@uvigo.es
} 
Here we model a three fir oligopoly (the Spanish fertilizer industry from 1976 to 1988) which was subject to price regulation. A theoretical and econometric model is developed in order to identify simultaneously the behaviour of the firm and the degree to which regulation constrained the price. The collusive marketsharing arrangements involving asymmetric firms and the less collusive outcomes of Cournot and Stackelberg, together with their constrained counterparts, are considered as particular behavioural hypotheses. The estimation of an aggregated and a disaggregated version of the model, by General Method of Moments (GMM) techniques, leads us to identify the regulation-constrained Stackelberg equilibrium as the most likely outcome given the data of the market.

This paper is organized as follows. Section 2 summarizes the characteristics of the industry. Section 3 analyzes the working of the industry and the price regulation. Section 4 is aimed at developing the theoretical and econometric framework. Section 5 specifie the econometric model and considers the estimation strategy. Section 6 presents the results of the estimation and in Section 7 some concluding comments are presented. Appendix A and Appendix B consider, respectively, the demand specificatio in the presence of international competition restricted by the trade policy, and the econometric treatment of the firms expectations. Finally, Appendix C gives some details on the data employed.

\section{Industry characteristics}

Our data (1976-1988) cover practically the entire period in which the industry can be considered a typical oligopoly, protected from foreign competition by high barriers until 1986. The industry had been consolidated in the sixties, with the support of the authorities with the aim of substituting the high imports by home production. At the beginning of the seventies supply became concentrated in three firms one of them state owned, and prices were regulated. By 1989, as a result of a process of mergers and the selling up of the public participation, the industry became a single fir that went bankrupt at the beginning of the nineties.

The industry can be considered as the producer of two main substitute homogeneous goods, nitrogenous fertilizers and compound fertilizers ${ }^{1}$, even though we shall limit our analysis to the market of the firs good (see the discussion of this issue in Section 4).

\footnotetext{
${ }^{1}$ Every type of fertilizer was sold, in fact, presenting a number of sub-varieties that differed in their content of basic chemical elements. We aggregate the sub-varieties of each group in a single composite commodity. Note that this can be done because every fir produced positive quantities of most of the sub-varieties, and prices tended to reflec only the differences in chemical composition. In addition, the firm did not show a geographical specialization of their productive capacities, which would have implied a better treatment of the industry as a geographically differentiated one (on all this, see MINER (1985)).
} 


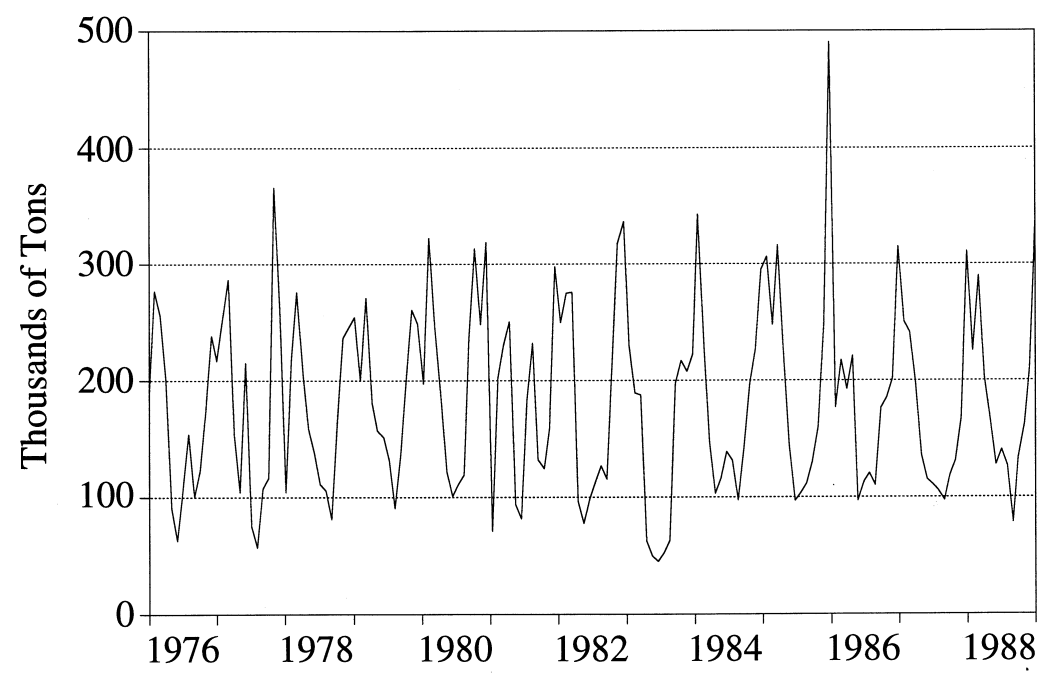

Fig. 1. Demand for nitrogenous fertilizers.

Nitrogenous fertilizers were, at the time of the analysis, a mature product, with a highly seasonal but stationary demand (see Fig. 1). High tariff and non-tariff barriers to foreign competition kept imports at a negligible level until Spain became a member of the European Community in 1986 (see Fig. 2). From 1986

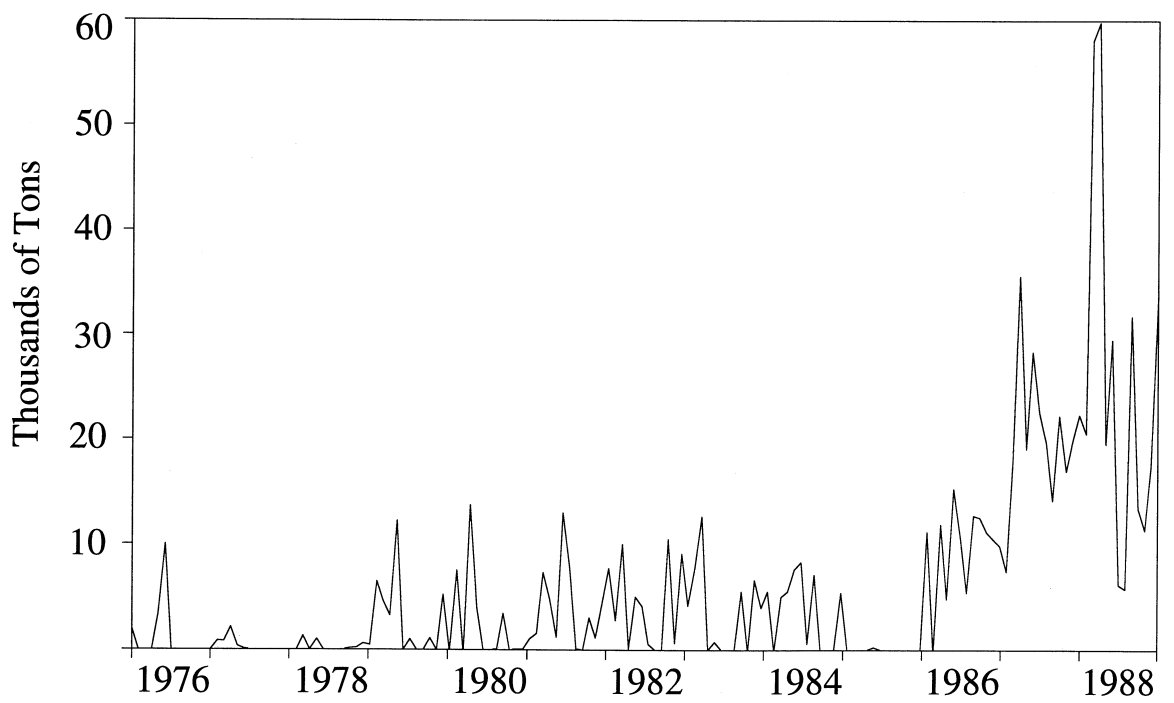

Fig. 2. Imports of nitrogenous fertilizers. 


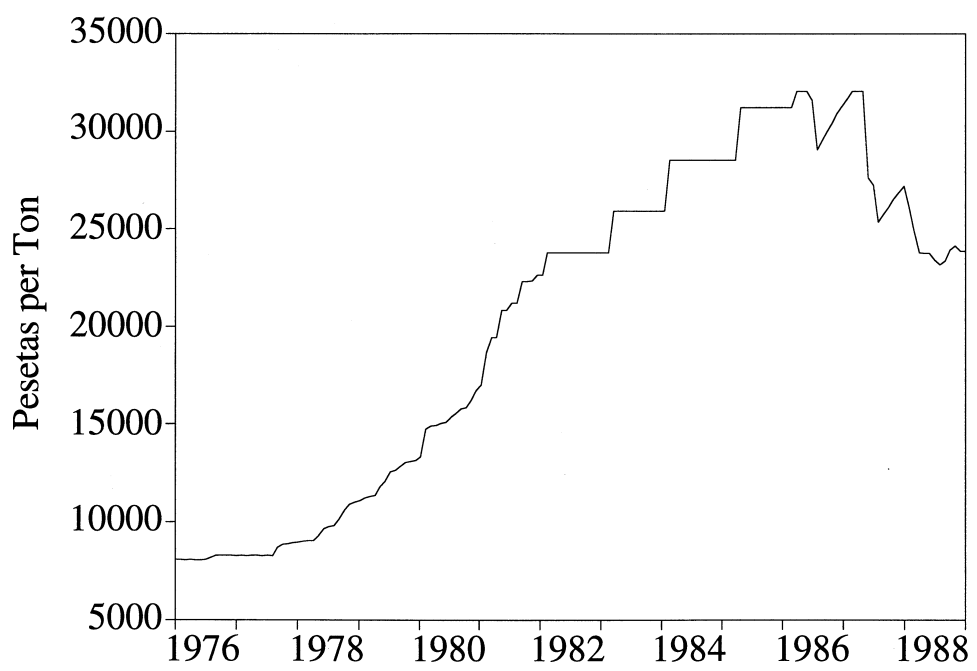

Fig. 3. Price evolution of the nitrogenous fertilizers.

on, barriers were progressively lessened, and price regulation was abandoned the following year. The prices increased steadily until 1986, and fell after that year, presumably as a result of the combination of cost changes and the new competitive pressure (see Fig. 3).

In the period under review, $70 \%$ of the supply of nitrogenous fertilizers was concentrated in three firm (ENFERSA, ERT and CROS), which accounted for $42 \%, 18 \%$ and $10 \%$ of the market respectively. ENFERSA was state owned, and all three were also active in the market for compound fertilizers, where they had shares inversely related to the previous ones. Their shares were remarkably stable over time (see Fig. 4).

Public intervention in the industry was strong. There were subsidies for farmers, as well as for producers for the acquisition of certain inputs and for investment. Most of all, there was also price regulation.

\section{Industry working and regulation: facts and hypotheses.}

The price regulation took the form of price ceilings, the firm being free to choose their prices at or below the ceiling. The regulator was a commission of the Ministry of Economy (the "Junta Superior de Precios"). The set of observable facts that characterized the price controls can be summarized as follows. Firstly, there was not any public statement about the rules to establish the regulated prices. When regulation started, industry prices at the time were more or less accepted as 


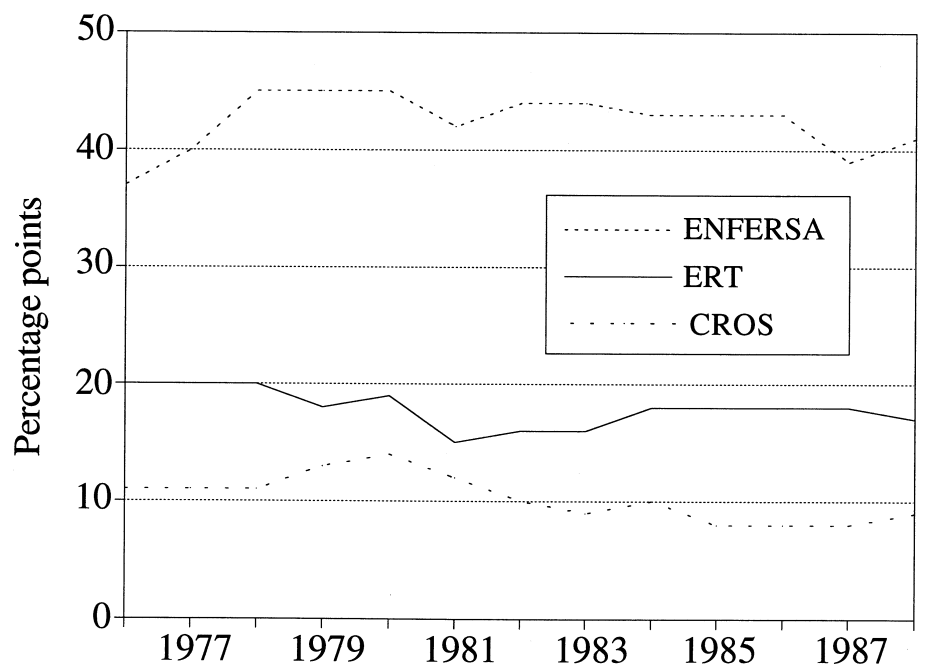

Fig. 4. Market shares of the three firms

the maximum prices. However, it is likely that those prices were already influence by public interventions. Secondly, the regulator proceeded at irregular intervals to raise the maximum prices in order to take inflatio into account. Occasionally, the regulator undertook cost and cost evolution studies, but there is no clear information as to whether they were used. Thirdly, employers were organized in a trade association that was allowed to present its proposals to the regulator before every price change. On each occasion the firm put forward jointly a price increase, in percentage terms, and the regulator proceeded by authorizing an increase which was somewhat lower. Fourthly, the real transaction prices did not at any moment significantl differ from the maximum approved prices $^{2}$.

This is basically a price-cap regulation scheme that did not, however, include any of the usual automatic indexing rules of the price-caps. Probably, the aim was to apply some "cost-of-service" (or "rate-of-return") regulation target, and some discussion on the evolution of the input prices was allowed. The result can be seen as a mixed mechanism with peculiar incentive properties. During the periods in which the price remained fixed the firm were residual claimants of their cost

${ }^{2}$ Fig. 3 depicts real transaction prices as collected by the Ministry of Agriculture. When compared with the maximum prices until 1981, there only appear very small monthly differences probably due to the effect of some slight seasonal discounts (see footnote 10). In any case, no signs of price wars can be found. From 1981 to 1986, the Ministry considered it sufficien to quote directly maximum prices as real transaction prices (see the steps). 
savings. When the reviews took place, the firm had the opportunity to modify their rents using their information advantages ${ }^{3}$.

One possibility is that the firm and the regulator engaged in some bargaining during the price reviews, whose repetition over time poses some difficul questions. In particular it raises the possibility of a changing regulatory outcome, either because the regulator learnt over time or because political and administrative pressures influence its price target at each moment. However, the bargaining processes could also give rise to a stable regulatory outcome, the statements of the firm being only a revelation device used by the regulator. It must also be noted that the apparent price divergences cannot even be taken as definit proof of real conflict For instance, the firm could simply have proposed the price increments that would be accepted, augmented in advance by the amount by which they knew the regulator was going to reduce their proposal. So, we are left with a broad range of possibilities, from an ineffective regulatory price ceiling to more constraining outcomes, either stable or varying over time. Given this scenario, before building our model we need to formulate our general hypotheses on the working of the industry and the regulatory mechanism.

Firstly, as far as the firm are concerned, the evidence (absence of price wars) indicates that the allocations reached must be considered self-enforcing agreements, that were effectively adhered to by the firm over time. Therefore, we will suppose that the firm agree explicitly on a (desired) unique price and on a repartition of the corresponding quantities to be produced, i.e., the market shares. But the ability of firm to communicate among each other is not a warranty of agreeing on full collusive outcomes. The firm knew the individual incentives to undercut some price levels, and they were conscious of the difficultie of detecting and efficientl punishing these undercuts. We will therefore assume that the firm either set a collusive outcome or simply agreed on a less than collusive price level.

In this context, it seems natural to consider as possible equilibrium outcomes all the well known Nash equilibriums in quantities. The highest degree of collusion will be represented by the market-sharing arrangements in the frontier of profit and the less collusive outcomes by the Cournot and Stackelberg solutions ${ }^{4}$. The Stackelberg equilibrium concept deserves special attention because the state owned fir was created in 1973, by a merger of several smaller firms This can perhaps be envisaged as a firs move giving leader advantages in capacity to this firm

\footnotetext{
${ }^{3}$ One can guess that the firm had greater knowledge about the evolution of demand and the input prices. This suggests the importance of the adverse selection constraint of the regulator, and the relevance of an incentive mechanism to trade off effort inducement and rent extraction (see Laffont and Tirole (1993)).

${ }^{4}$ See Schmalensee (1987) on collusive outcomes with asymmetric firms and Tirole (1988) on their sustainability under trigger strategies. Cournot and Stackelberg can be seen as situations in which firm have no incentive to start short run price wars given their capacities (see Kreps and Scheinkman (1983); Dixit (1979), (1980)).
} 
Secondly, as far as the regulatory agency is concerned, the facts seem to suggest a social welfare maximizing regulator, aimed at extracting rents from the firms but we cannot preclude a priori that the regulator simply accepted and passed on the firms price proposals (perhaps because it was a regulator captured by the industry). Our treatment of the regulator will therefore avoid establishing any specifi model (or a set of specifi models) of its behaviour. Instead, we will focus on the extent to which its decisions constrained the outcome desired by the firm ${ }^{5}$. It is important to note, however, that our framework will imply that we confin ourselves to a class of regulation equilibrium outcomes which are stable over time ${ }^{6}$.

Thirdly, as far as the interaction between the firm and the regulator is concerned, we will assume as a starting point that the firm had a well define desired equilibrium allocation (that is, the price and quantities that the firm would implement if the regulator behaved simply as an auctioneer). Therefore, if the price was going to be constrained to a lower level, the firm were forced-iconflic had to be avoided - tconsider the sharing of the production of an additional output. We will take into account forms (mainly proportional) of sharing this output, but the properties of these "second-best" allocations remain in most cases a theoretically open question (however, see Daughety (1984) on one of these equilibriums). In any case, incentives to undercut the agreed price can be considered prevented again by trigger strategies.

To sum up, we address the problem of identifying the behaviour of the firm assuming that they agreed on some specifi self-enforcing allocation. But, at the same time, we make no assumption regarding the degree to which the regulator constrained the price desired by the firms We will even allow that the regulator acted simply as an institutional device to obtain a unique price. Therefore, the identificatio of behaviour includes the problem of identificatio of the effectiveness of the regulation. In the rest of this paper, we shall refer to the two polar cases as situations of binding and non-binding regulation.

\section{Theoretical framework}

In this section we shall develop a theoretical and econometric model for the industry. Firstly, we establish the framework to deal with the demand. Secondly,

\footnotetext{
${ }^{5}$ It seems rather difficul to fin a sensible set of equilibrium concepts for the regulatory outcomes. For instance, the previous discussion on the regulatory mechanism suggests the likely relevance of some repeated bargaining perfect bayesian equilibrium. But, as is known, it is difficul to fin satisfactory unique solutions for these types of models (see Fudemberg and Tirole (1993)).

${ }^{6}$ This is a strong constraint, that could possibly be relaxed by adding an equation aimed at modelling the regulator parameter as a result of the bargaining processes. But this will further complicate the model and it is a rather pointless exercise in the absence of a more definit theoretical framework for the regulatory process.
} 
we present our assumptions about the technology of the firms Thirdly, we consider the timing of the decisions. Fourthly we set the likely equilibrium outcomes that we will consider as possible non-binding regulation results. Fifthly, we study their constrained counterparts. Finally, we also build an aggregated version of the model.

In the rest of this paper, only the nitrogenous fertilizers market is considered. This focus, which cannot be avoided for data reasons, deserves a word of caution. The scenario of three firm competing in two demand-related markets (nitrogenous and compound fertilizers), even with the assumption of independent constant marginal costs of producing the goods, raises the question of the relevance of multimarket interaction ${ }^{7}$. The available evidence points clearly to multimarket equilibrium outcomes: price wars were absent from both markets, the maximum prices tended to move in a parallel way, and the uneven fir shares across markets can be an indication of cost-advantages-based allocations. This seems to suggest that, in principle, equilibriums should be define and characterized across both markets. However, there is an asymmetry feature of the markets which makes treating the nitrogenous fertilizers market in isolation a sensible alternative.

The demand for nitrogenous fertilizers shows a strong effect of the price of compound fertilizers. But there is some evidence of a weaker effect in the opposite direction, perhaps because of the relatively innovative character of the compound fertilizers, that were used increasingly during the period. This gives some reliability to what can be gathered from the modelled market. While the analyzed outcomes will be clearly influence by the equilibrium in the other market, and will constitute only part of the entire picture, they will be a legitimate approximation to what is happening in the whole industry ${ }^{8}$.

\footnotetext{
${ }^{7}$ On the one hand, any fir endowed with some market power and operating in both markets will take into account the demand-link between the two markets. As a consequence, the competing firm are likely to internalize these links in their strategic interaction (see, for example, Bulow et al. (1985)). On the other hand, multimarket contact is likely to facilitate collusive outcomes. For instance, Berheim and Whiston (1990) show this effect, and emphasize its reinforcement when some fir asymmetries are present.

${ }^{8}$ Given a multimarket equilibrium in two related markets, if there is some asymmetry in the price cross-effects in demands, the interaction effects are more important to characterize the equilibrium in the market that provokes the strongest externality than in the other. More formally, suppose that there are two related markets with demands $q^{\mathrm{N}}=q^{\mathrm{N}}\left(p^{\mathrm{N}}, p^{\mathrm{C}}\right)$ and $q^{\mathrm{C}}=q^{\mathrm{C}}\left(p^{\mathrm{N}}, p^{\mathrm{C}}\right)$, and let $\pi_{i}\left(q_{i}^{\mathrm{N}}, q_{j}^{\mathrm{N}}, q_{i}^{\mathrm{C}}, q_{j}^{\mathrm{C}}\right)$ be the global profi function of competitor $i$ ( $j$ indexes the output of his rivals). A (quantities) multimarket equilibrium will imply, for example, the following firs order condition for fir $i$ in market $\mathrm{N}$,

$$
\frac{\partial \pi_{i}}{\partial q_{i}^{\mathrm{N}}}=p^{\mathrm{N}}+q_{i}^{\mathrm{N}} \frac{\partial p^{\mathrm{N}}}{\partial q^{\mathrm{N}}} \frac{\partial q^{\mathrm{N}}}{\partial q_{i}^{\mathrm{N}}}-c_{i}^{\mathrm{N}}+q_{i}^{\mathrm{C}} \frac{\partial p^{\mathrm{C}}}{\partial q^{\mathrm{N}}} \frac{\partial q^{\mathrm{N}}}{\partial q_{i}^{\mathrm{N}}}=0
$$

A sufficien condition for vanishing the last term is that $\left(\partial q^{\mathrm{C}} / \partial p^{\mathrm{N}}\right)$ be small enough, independently of $\left(\partial q^{\mathrm{N}} / \partial p^{\mathrm{C}}\right)$ being strong or not. In that case, the firs order conditions in the $\mathrm{N}$ market will tend to form a system of equations relating exclusively $p^{\mathrm{N}}$ and the $q^{\mathrm{N}}$ quantities. However, the equilibrium allocation in $\mathrm{C}$ influence the outcome in $\mathrm{N}$ through the demand function.
} 


\subsection{The demand side}

On the demand side, we will assume that the domestic nitrogenous fertilizers can be considered a homogeneous good imperfectly substitutable by the imports of the same good. As far as imports are concerned, we shall assume that the domestic producers acted parametrically with respect to the international price inclusive of tariffs, and that the actual imports depend on that price and the rationing imposed by administrative methods. In this setting, the relevant domestic demand must include the international price inclusive of tariffs and an indicator of the likely spillovers coming from the rationed imports (see Appendix A for details). This demand function, if rightly specified embodies all the relevant information about the changes in trade policy throughout the period (e.g. dismantling of trade barriers during the last years) from the point of view of the optimization problem of the domestic firm 9 .

Demand, specifie in quantities, will be modelled by the following linear relationship,

$$
q=a+z^{\prime} \alpha-b p
$$

where $a$ and $b$ are positive parameters, $z$ represents the whole vector of variables that shift demand, and $\alpha$ its associated parameters. In Section 5 we detail the specificatio of this relationship, including the treatment of seasonality.

\subsection{The firm' technology}

According to a long run view of the oligopolist interaction, we will consider capital as a variable input. In addition, we will assume that every input is used in fixe proportions to output. Therefore, the firms marginal costs will be constant over the production ranges and can be specifie as a linear function of the input prices. Furthermore, we will allow the firm to experience different marginal costs because of different input prices or technological differences (input coefficient ). That is, for every fir $i$ we will take marginal cost to be,

$$
c_{i}=w_{i} \frac{N_{i}}{q_{i}}+p_{E i} \frac{E_{i}}{q_{i}}+u c_{i} \frac{p_{K i}^{0} K_{i}}{q_{i}}
$$

where $w$ represents the labour cost per worker and $N$ the number of workers, $p_{E}$ the price of a specifi material and $E$ its quantity (here we isolate a single material

\footnotetext{
${ }^{9}$ However, the progressive trade policy changes of the last three years of the sample may have also induced changes in behaviour. We will ignore this possibility because of the lack of enough degrees of freedom to test models with switching behaviour for such a short period.
} 
for simplicity, in fact they can be several), and $u c$ the user cost of capital (the capital being valued at prices of some base year) define as,

$$
u c=\left(r+d-(1-d) \pi_{+1}\right) \frac{p_{K}}{p_{K}^{0}}=\left(r+d-(1-d) \pi_{+1}\right) \prod_{s=1}^{t}\left(1+\pi_{s}\right)
$$

where $r$ stands for the relevant interest rate, $d$ for the depreciation rate, $p_{k}$ for the current price of the capital goods, and $\pi_{s}$ for its rate of increase in period $s$. Replacing the unknown coefficient by parameters to be estimated, we have,

$$
c_{i}=\beta_{i 1} w_{i}+p_{E i}^{\prime} \beta_{i 2}+\beta_{i 3} u c_{i} i=1,2,3
$$

which will be our specificatio of firms marginal costs.

\subsection{Timing}

Some words about the timing of the optimal decisions. On the one hand, we will ignore the possibility of prices varying seasonally. The reason is that firm seem to have avoided this practice ${ }^{10}$. On the other hand, and more important, we will assume that the optimization problem of the firm is separable over time in a number of maximization problems equal to the number of price reviews. The demand schedule is known by the firm which, in addition, are endowed at the price reviews with expectations about the values of all the demand and cost shift variables. We will suppose that these expectations are given by a forecast of the average values of the variables during the interval between reviews, from which the firm consider that the actual per-period values will diverge only by unpredictable random shocks. These forecasts will be only actualized before the price reviews. So, the firm have an expectation on the (average) output they will be able to sell at each price and, given behaviour, they are able at the price reviews to assess their optimal price (quantities) for the number of periods ahead in which the maximum price will remain sticky. It is this optimal price that they will try to pass on.

Note that, given our assumptions, firm could no be better off by selecting the optimal values at each period if it were to be done before knowing the realization of the unexpected shock. Therefore, there is no incentive to revise the optimal

\footnotetext{
${ }^{10}$ In fact, by 1986, a new system of varying maximum prices according to a seasonal schedule was announced by the authorities to replace the old system of a constant maximum price. The alleged reason was to favour the access of the farmers to price discounts according to the storage costs they assumed. Several reasons for which producers tended to reduce to a minimum the seasonal price variations can be suggested. Firstly, optimal intertemporal pricing tends to reduce price variations for storable commodities in the presence of short-run increasing marginal costs (see Phlips (1983)). Secondly, firm could fin it more difficul to monitor an agreement with a scheme of discounts. Thirdly, firm could fin that by avoiding raising prices in the high-demand season, temptations to undercut prices were prevented (see Rotemberg and Saloner (1986)).
} 
values during the interval between price reviews. In this context, all the demand (and cost) variables in this section must be considered expectations, and the expressions can be thought of as representing interchangeably interval or perperiod relationships. These assumptions will allow us using the available information at its highest degree of temporal disaggregation. The way to do so and the econometric implications will be considered in Section 5.

\subsection{Non-binding regulation}

We should now specify the behaviour of the firms Consider firs the case in which regulation is not binding. In this setting, we will take into account two types of possible equilibrium outcomes: the full collusive market-sharing arrangements and the less collusive equilibriums of Cournot and Stackelberg. We will now show that these outcomes may be seen as determining particular values and constraints on the parameters of a general linear simultaneous econometric model (as, for example, in Gasmi et al. (1992)).

The efficien market-sharing arrangements may be characterized from the resolution of the following program,

$$
\underset{q_{1}, q_{2}, q_{3}}{\operatorname{Max}} \pi_{1}=p(q) q_{1}-c_{1} q_{1} \text { s.t. } \begin{aligned}
& \pi_{2} \geqslant \bar{\pi}_{2} \\
& \pi_{3} \geqslant \bar{\pi}_{3}
\end{aligned}
$$

that is, the maximization of fir 1 profit subject to profi targets for firm 2 and $3^{11}$. The firs order conditions of this problem, given the specificatio of the demand, may be written as,

$$
-\sum_{j=1}^{3} \frac{1}{b} \rho_{j} q_{j}+\rho_{i} p-\rho_{i} c_{i}=0 \quad i=1,2,3
$$

with $\rho_{1}=1$, and where the $\rho$ 's represent the Lagrange multipliers. Each couple of values of the $\rho_{2}$ and $\rho_{3}$ depict a point on the frontier of profits

The firs order conditions may be rearranged in the following way,

$$
p=\frac{1}{b \rho_{i}} \sum_{j=1}^{3} \rho_{j} q_{j}+c_{i} i=1,2,3
$$

which makes their behavioural interpretation clearer: price will be set over marginal costs according to the specifi market-sharing arrangement. If we can consider the $\rho$ 's stable over time, this equations provide a test that involves observable variables (price, quantities and costs) to assess the likelihood of this type of allocations. The stability of the $\rho$ 's seems a realistic assumption if the

\footnotetext{
${ }^{11}$ There are other ways to characterize the same equilibrium points (for instance, fir 1 choosing the price and shares that maximize its profit for given profi targets for firm 2 and 3), but we fin the use of the previous format advantageous.
} 
(asymmetric) fir unit costs grow more or less at the same pace. In this setting, firm could easily agree on increasing the price by the same amount as costs, without changing the distribution of profits In addition, it can be shown that the $\rho$ 's equal the ratios of the price-cost margin of fir 1 with respect to the margins of the other firms and the stability of the relative margins seems a sensible rule to apply over time for the sake of coordination.

Let us now consider the outcomes of Cournot and Stackelberg. The Cournot equilibrium can be characterized from the resolution of the individual programs,

$$
\operatorname{Max}_{q_{i}} \pi_{i}=p(q) q_{i}-c_{i} q_{i} \quad i=1,2,3
$$

when firm take as given the output of the rivals. Given our demand specification the firms firs order equations can be written as,

$$
p=\frac{1}{b} q_{i}+c_{i} i=1,2,3
$$

As far as the Stackelberg equilibrium is concerned assume, without loss of generality, that fir 1 is the leader and firm 2 and 3 the followers. The behaviour of both followers will be characterized by equations like Eq. (2). Then, it is easy to show that the behaviour of the leader can be characterized from the resolution of the program,

$$
\underset{q_{1}}{\operatorname{Max}} \pi_{1}=p(q) q_{1}-c_{1} q_{1} \text { s.t. } p(q)=\frac{a+z^{\prime} \alpha}{3 b}-\frac{1}{3 b} q_{1}+\frac{1}{3}\left(c_{2}+c_{3}\right)
$$

This will give the leader firs order condition,

$$
p=\frac{1}{3 b} q_{1}+c_{1}
$$

So, let us formulate a general linear simultaneous econometric model integrated by four equations, the demand relationship and the three individual price equations. In a conventional form, this model can be written as,

$$
\begin{aligned}
& q_{1}+q_{2}+q_{3}+b p-z^{\prime} \alpha-a \quad=\epsilon_{0} \\
& \gamma_{11} q_{1}+\gamma_{12} q_{2}+\gamma_{13} q_{3}-p+\beta_{11} w_{1}+p_{E}^{\prime} \beta_{12}+\beta_{13} u c_{1}=\epsilon_{1} \\
& \gamma_{21} q_{1}+\gamma_{22} q_{2}+\gamma_{23} q_{3}-p+\beta_{21} w_{2}+p_{E}^{\prime} \beta_{22}+\beta_{23} u c_{2}=\epsilon_{2} \\
& \gamma_{31} q_{1}+\gamma_{32} q_{2}+\gamma_{33} q_{3}-p+\beta_{31} w_{3}+p_{E}^{\prime} \beta_{32}+\beta_{33} u c_{3}=\epsilon_{3}
\end{aligned}
$$

where the $\epsilon$ 's are random disturbances.

The model has four endogenous variables $\left(q_{1}, q_{2}, q_{3}\right.$ and $\left.p\right)$, some predetermined cost variables and a number of predetermined demand variables equal to the length of $z^{\prime}$ (plus the constant). It is easy to verify that the parameters of this general model are identified In fact every equation meets the order and rank conditions and they are all over-identified 
Table 1

The output parameters of the linear model under different behavioural assumptions

\begin{tabular}{|c|c|c|c|c|c|c|c|c|c|}
\hline & $\gamma_{11}$ & $\gamma_{12}$ & $\gamma_{13}$ & $\gamma_{21}$ & $\gamma_{22}$ & $\gamma_{23}$ & $\gamma_{31}$ & $\gamma_{32}$ & $\gamma_{33}$ \\
\hline \multicolumn{10}{|c|}{ Non-binding regulation: } \\
\hline Market sharing & $\frac{1}{b}$ & $\frac{\rho_{2}}{b}$ & $\frac{\rho_{3}}{b}$ & $\frac{1}{b \rho_{2}}$ & $\frac{1}{b}$ & $\frac{\rho_{3}}{b \rho_{2}}$ & $\frac{1}{b \rho_{3}}$ & $\frac{\rho_{2}}{b \rho_{3}}$ & $\frac{1}{b}$ \\
\hline Cournot & $\frac{1}{b}$ & 0 & 0 & 0 & $\frac{1}{b}$ & 0 & 0 & 0 & $\frac{1}{b}$ \\
\hline Stackelberg & $\frac{1}{3 b}$ & 0 & 0 & 0 & $\frac{1}{b}$ & 0 & 0 & 0 & $\frac{1}{b}$ \\
\hline
\end{tabular}

Binding regulation:

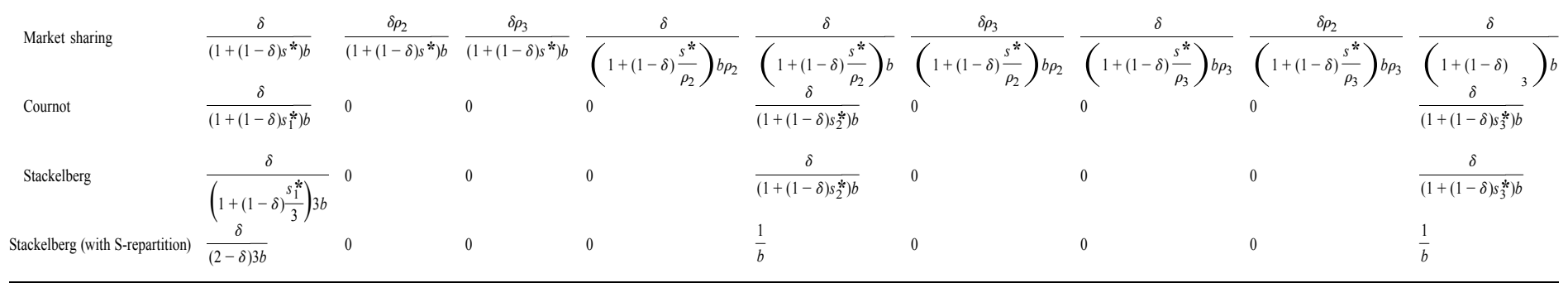

Notes: $s^{*}=s_{1}^{*}+\rho_{2} s_{2}^{*}+\rho_{3} s_{3}^{*}$. 
Table 2

Constraints on the output parameters under the different behavioural assumptions

\begin{tabular}{|c|c|c|}
\hline & \multicolumn{2}{|l|}{ Output parameters } \\
\hline & Own output & Cross outputs \\
\hline \multicolumn{3}{|l|}{ Non-binding regulation: } \\
\hline Market sharing & $\gamma_{11}=\gamma_{22}=\gamma_{33}=\frac{1}{b}$ & $\gamma_{12} \gamma_{21}=\gamma_{13} \gamma_{31}=\gamma_{23} \gamma_{32}=\frac{1}{b^{2}}$ \\
\hline Cournot & $\gamma_{11}=\gamma_{22}=\gamma_{33}=\frac{1}{b}$ & $\gamma_{12}=\gamma_{13}=\gamma_{21}=\gamma_{23}=\gamma_{31}=\gamma_{32}=0$ \\
\hline $\begin{array}{l}\text { Stackelberg } \\
\text { Binding reoulation. }\end{array}$ & $\gamma_{11}=\frac{1}{3 b}, \gamma_{22}=\gamma_{33}=\frac{1}{b}$ & $\gamma_{12}=\gamma_{13}=\gamma_{21}=\gamma_{23}=\gamma_{31}=\gamma_{32}=0$ \\
\hline \multicolumn{3}{|l|}{ Binding regulation: } \\
\hline Market sharing & & $\gamma_{12} \gamma_{21}=\gamma_{11} \gamma_{22}, \gamma_{13} \gamma_{31}=\gamma_{11} \gamma_{33}, \gamma_{23} \gamma_{32}=\gamma_{22} \gamma_{33}$ \\
\hline Cournot & & $\gamma_{12}=\gamma_{13}=\gamma_{21}=\gamma_{23}=\gamma_{31}=\gamma_{32}=0$ \\
\hline Stackelberg & & $\gamma_{12}=\gamma_{13}=\gamma_{21}=\gamma_{23}=\gamma_{31}=\gamma_{32}=0$ \\
\hline Stackelberg (with S-repartition) & $\gamma_{22}=\gamma_{33}=\frac{1}{b}$ & $\gamma_{12}=\gamma_{13}=\gamma_{21}=\gamma_{23}=\gamma_{31}=\gamma_{32}=0$ \\
\hline
\end{tabular}

Each one of the considered equilibrium outcomes imposes a number of constraints on this general model. These constraints involve the price parameter of the demand equation and the output parameters of the price equations. Table 1 gives the output parameters of the general model in terms of the underlying parameters, and Table 2 gives the corresponding constraints. They are simply non-linear cross-equation constraints combined with some exclusion constrains (the cross-output parameters in the cases of Cournot and Stackelberg).

\subsection{Binding regulation}

Let us turn now to the case in which regulation is binding. In this case, the observed price and quantities will not coincide with the desired allocation (that is, the price and quantities that the firm would implement if the regulator behaved simply as an auctioneer). Here, we shall make two basic assumptions: that the firm would reach a well define equilibrium if regulation were not binding, and that the regulator sets the maximum price by reducing the desired price by a fixe proportion. The firs assumption gives a precise content to the concept of desired price. In particular, we will consider as many possible desired prices as nonregulation-constrained outcomes we have considered. The second assumption will be used as a useful feature to develop the conditions for the identificatio of behaviour in the presence of binding regulation.

Binding regulation will therefore be characterized by the following relationship,

$$
p=\delta p * \text { with } \delta \leqslant 1
$$

that is, the $p$ ceiling price will be a constant proportion of the $p^{*}$ desired price. At this price demand will be greater than it would have been at the desired price, and 
the additional output to be produced may be written as a function of the regulated price and the delta parameter in the following way,

$$
q-q^{*}=b\left(\frac{1-\delta}{\delta}\right) p
$$

The firms problem is therefore the distribution of this additional output that the market will demand. With constant marginal costs and positive margins, every fir is willing to take on the production of this additional output. Accordingly, we need to specify what will be the repartition rule. We will consider two possibilities.

Firstly, we will consider that the firm divide the output increment according to their shares in the non-binding-regulation equilibrium solution. Schmalensee (1987) suggested that reducing output while maintaining the market shares at their non-collusive level could be a sensible collusion "technology". Here, in an inverse but similar way, we assume that expanding output proportionately from the desired allocation may be a simple procedure for coordination. In this case, the following relationship between the observed and desired quantities will hold,

$$
q_{i}=s_{i}^{*} q=q_{i}^{*}+s_{i}^{*} b\left(\frac{1-\delta}{\delta}\right) p
$$

where $s *$ stands for the equilibrium shares. Then the equations that characterize the different (desired) equilibrium outcomes may be rewritten under binding regulation in terms of the observable price and quantities and the delta parameter.

Eq. (1) will be transformed into,

$$
p=\frac{\delta}{\mu_{i} b \rho_{i}} \sum_{j=1}^{3} \rho_{j} q_{j}+\frac{\delta}{\mu_{i}} c_{i} \quad i=1,2,3
$$

where $\mu_{i}=1+(1-\delta) \frac{1}{\rho_{i}} \sum_{j} s_{j}^{*} \rho_{j}$. Eq. (2) will give,

$$
p=\frac{\delta}{\mu_{i} b} q_{i}+\frac{\delta}{\mu_{i}} c_{i} i=1,2,3
$$

with $\mu_{i}=1+(1-\delta) s_{i}^{*}$, and Eq. (3) for the Stackelberg leader will be,

$$
p=\frac{\delta}{3 \mu_{1} b} q_{1}+\frac{\delta}{\mu_{1}} c_{1}
$$

with $\mu_{1}=1+(1-\delta)\left(s_{1}^{*} / 3\right)$.

Secondly, we may consider an alternative for the situation in which there is a Stackelberg leader. If a fir plays this role in the determination of the nonbinding-regulation outcome, it seems natural to consider that it will also be able to assume this role in the repartition of the additional output. In this case, the leader would select the best point on the reaction curves of the rivals that is compatible with the constraint imposed by regulation (see Daughety (1984)). This will modify the previous shares, and the new equations for the leader and the followers will be, 


$$
p=\frac{\delta}{3 \mu_{1} b} q_{1}+\frac{\delta}{\mu_{1}} c_{1} \text { and } p=\frac{1}{b} q_{i}+c_{i} i=2,3
$$

where $\mu_{1}=(2-\delta)$.

This completes the examination of the equilibrium outcomes under bindingregulation. As before, Table 1 gives the parameters of the general model in terms of the underlying parameters, and Table 2 summarizes the constraints they impose. Here there appears to be a specifi characteristic to be noted. The market-sharing and the second Stackelberg (Stackelberg with S-repartition) equilibriums imply, as before, some non-linear cross-equation constraints. But, Cournot and Stackelberg under binding regulation only imply the same set of exclusion constraints (the cross-output parameters). Therefore, selection between these two equilibrium concepts will not be possible on the same grounds as in the other cases. This discussion will be continued in Section 5 .

Fig. 5 gives a version of the equilibrium outcomes considered so far. The figur is drawn under the simplifying assumption that firm 2 and 3 are identical. Consider firstl the non-binding setting. The curve closer to the origin in the $q$-plane is the convex Pareto frontier of profit when firm have constant but

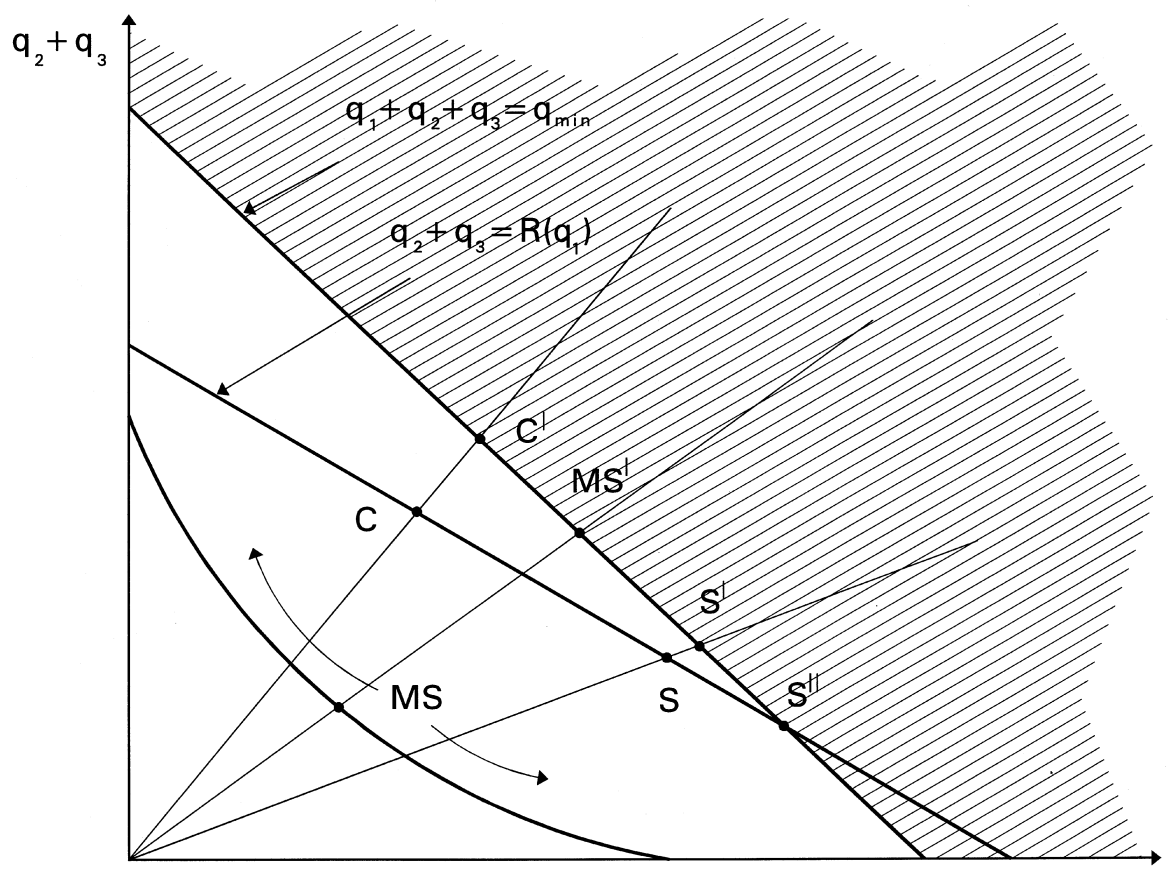

$\mathrm{q}_{1}$

Fig. 5. Market outcomes under binding and non-binding regulation. 
different marginal costs. A market-sharing arrangement (MS) will lie on it. The line to the right of this curve represents the reaction curve of firm 2 and 3 to fir 1. The unconstrained Cournot (C) and Stackelberg (S) equilibriums will lie on it. Consider now the binding regulation situation. If regulation is binding, there is a maximum price or, equivalently, a minimum output to be produced. Only the shaded area of the $q$-plane represent outcomes which are compatible with the price constraint. On the frontier of this area, we will consider points that represent the repartition of the additional output to be produced according to the shares of the desired unconstrained equilibriums $\left(\mathrm{MS}^{\prime}, \mathrm{C}^{\prime}, \mathrm{S}^{\prime}\right)$ and an equilibrium on the former reaction curve to the leader decisions ( $\mathrm{S}^{\prime \prime}$, Stackelberg with S-repartition).

\subsection{An aggregated model}

All the equations developed so far to represent equilibrium solutions have been shown to be particular cases of a general linear simultaneous econometric model. In each case, every structural parameter is identified even the regulation parameter. However, the coefficient of the linear model are, in general, non-linear functions of the structural parameters. In addition, the identificatio of the general econometric model hinges, both in the non-binding and binding cases, on the availability of different input prices for each firm If input prices were the same, the sole difference among the three individual equations of the general model would be the parameters to be estimated. As identificatio may prove to be difficul in these circumstances, and our disaggregated data are not so reliable, we will also develop an aggregated version of the model. The empirical part of this paper will be based on the combined use of the two versions.

Eq. (1), conveniently rearranged, gives the output to be produced for each fir as a function of its cost, the price set, the parameters representing behaviour and the shares of the firms

$$
q_{i}=\frac{b}{1+\frac{\sum_{j \neq i} \rho_{j} s_{j}}{\rho_{i} s_{i}}}\left(p-c_{i}\right) i=1,2,3
$$

Eq. (2) gives, similarly, $q_{i}=b\left(p-c_{i}\right)$ for $i=1,2$, 3, and Eq. (3) can be transformed into $q_{1}=3 b\left(p-c_{1}\right)$.

So, by aggregating quantities and findin the price in each non-binding equilibrium outcome, it becomes clear that the aggregate price equation can be put in the format,

$$
p=\frac{1}{b A} q+\frac{1}{A} \sum_{i} \omega_{i} c_{i}
$$

where $A=\sum_{i} \omega_{i}$ and the $\omega$ 's depend on behaviour. With a market-sharing 
arrangement, it is easy to check that $A=1$. Similarly, under Cournot $A=3$ and under Stackelberg $A=5$.

Now, if either the input prices are the same for every fir or we only dispose of an average of the input prices, we can formulate the following two equation simultaneous model,

$$
\begin{aligned}
q+b p-z^{\prime} \alpha-a & & =u_{0} \\
\gamma q-p & +\beta_{1} w+p_{E}^{\prime} \beta_{2}+\beta_{3} u_{c} & =u_{1}
\end{aligned}
$$

Testing behaviour with this model in a non-binding regulation setting amounts simply to a test of the values of the cross-constraints on the $b$ and $\gamma$ parameters. The market-sharing arrangement implies $\gamma=(1 / b)$, Cournot behaviour $\gamma=(1 / 3 b)$ and Stackelberg $\gamma=(1 / 5 b)$.

Taking Eq. (4) as a relationship among the desired variables, and replacing them by their expression in terms of the observed ones and the delta regulation parameter, we obtain,

$$
p=\frac{1}{b \varphi(A)} q+\frac{1}{\varphi(A)} \sum_{i} \omega_{i} c_{i}
$$

where $\varphi(A)=(1 / \delta)[A+(1-\delta)]$. Then, under binding regulation, the $\gamma$ parameter of the aggregated model will be a function of the behaviour and the constraint imposed by regulation. So, we cannot simultaneously identify these two aspects of the working of the market. However, the estimation of this model might still be useful. As $\delta \leqslant 1$, this implies that $A \leqslant \varphi(A)$, and some behavioural patterns could be excluded with the estimation of $\gamma$. Furthermore, with some a priori information about $\delta$, it is possible to speculate about the likely behaviour.

\section{Econometric specificatio and strategy.}

Nitrogenous fertilizers are an input for agricultural producers. Accordingly, we use a conditional demand for inputs approximation to formulate the demand equation. This is, by the way, the perspective adopted for most of the studies about the demand for fertilizers (see Burrell (1989) for a survey). We therefore need to decide which are the substitute and complementary inputs whose prices must be included in the equation, what is the right agricultural output measure, and what are the control variables. From a theoretical point of view, the demand relationship should be homogeneous of degree zero in the input prices. But, as we are working at a high degree of aggregation, we will not impose this constraint. We will simply verify to what extent this condition is approximately fulfilled

Our dependent variable will be the quantity of nitrogenous fertilizers (QNIT), in thousands of tons, sold in the domestic market and the (negligible) quantity sold in the foreign markets. We will be able to use indifferently the quantity sold either by 
all the producers or by our three main producers without any significan change. The demand for fertilizers is highly seasonal and, as our basic data are monthly, we will need to take this seasonality into account. This was accomplished in the firs phases of the work by the introduction of a set of monthly dummies, which were later constrained in estimation to a four period seasonal schedule (see Pazó, 1994).

Our main independent variable is the price of the nitrogenous fertilizers (PNIT). As far as the prices of the other inputs are concerned, we will take into account the price of the compound fertilizers (PCOMP), and the international price of the nitrogenous fertilizers inclusive of tariffs (PIMP), both substitute inputs, and the price of seeds (PSEED), a complementary input. The output on which we will condition demand will be the general agricultural output (AGOUT). Over time, two variables will be used to control for the heterogeneity of the crops and the exogenously determined productivity: the average quality of the cultivated areas (QUAL) and climatology (CLIM). In order to pick up the presumably important effects of the reduction in the non-tariff barriers on imports, we will also include separately within the equation an estimation of the ad-valorem tariff (T). We expect this variable to play the role of indicator of the evolution of the quantity restrictions on imports. The assumption is, of course, that the tariff and the non-tariff barriers on imports evolved similarly over time.

On the other hand, in the price equation (equations) we will have the price of the nitrogenous fertilizers as a dependent variable and the corresponding output measure (output measures) as the firs explanatory variable. As input price variables, we will include the price of fuel (PFUEL), the price of naphtha (PNAPH), the labour costs (WAGE) and the user cost of capital (UC).

The estimation of the demand relationship and the price equation (equations) sets a typical problem of simultaneous estimation that, however, presents some important econometric peculiarities. Output appears in the price equations as a key variable to identify the behaviour of the firm and the relevant output, given our theoretical discussion, is the expected (average) output at the moment the price is chosen. Since we only dispose of data for the observed sold output, on a monthly basis, we must study the conditions under which we can replace in our estimation the expected by the observed output.

According to our model, the observed monthly output will diverge from the relevant expected (average) output for two reasons. Firstly, by a seasonal systematic factor. Secondly, by a composite disturbance term with two components. The firs component is the forecasting error on the level of the average output incurred presumably at each review. This error will remain constant during the interval between reviews and we will assume it to be uncorrelated across reviews. The second component consists of the zero mean unexpected shocks around the forecasted mean. As a consequence of this structure, the composite disturbance term will be a zero mean error autocorrelated over time.

From the econometric point of view, this setting implies some consequences 
(see Appendix B for technical detail). Firstly, the replacement of the expected output by the actual output in the price equation must be accompanied by the inclusion of the seasonal dummies (to control for the systematic divergences), and the recognition that this output will be correlated with the (presumably autocorrelated) error term ${ }^{12}$. Secondly, endogenity plus a likely autocorrelated error term calls for a proper instrumental variables procedure of estimation. This is the reason for which we will use GMM techniques to obtain consistency (see Hansen (1982); Hansen and Singleton (1982) and the survey by Ogaki (1993)). Thirdly, the sticky price set in advance will be independent of the subsequent unexpected shocks and, in consequence, can be exogenous in the demand equation.

We shall now explain our econometric strategy to deal with the problem of identifying simultaneously the behaviour of the firm and the character of the regulation. In principle, the direct estimation of the disaggregated model should be sufficien to identify behaviour and the constraint imposed by regulation. All the parameters of the general linear model are identified and these parameters are in general non-linear functions of the underlying structural parameters that characterize the equilibrium outcomes. This is the situation both in the cases of non-binding and binding regulation, where the structural parameters include in the last case the $\delta$ regulation parameter. In this setting, each model could be estimated by non-linear methods and compared with the others. But most of the equilibrium outcomes imply, however, a set of specifi constraints on the parameters of the general linear model. Such equilibriums, then, can be tested against the general specificatio simply by testing the constraints they impose. There are two equilibriums, however, that impose the same (exclusion) constraints on the general model. These are the regulation constrained Cournot and Stackelberg outcomes, whose structural parameters turn out be exactly identifie under the exclusion constraints (i.e. the $k$ parameters of the linear model are in fact $k$ non-linear functions of the set of $k$ underlying parameters). If the constraints imposed by these two models could be accepted, all the others being rejected (as will in fact be the case, see Section 6), the selection between them should be based on the comparison of the estimates they give.

Unfortunately, data limitations prevent us from using the disaggregated model as an exclusive way to infer our conclusions. The identificatio of the parameters requires the use of the firms outputs and relies heavily on the availability of different input prices for each firm But, as can be appreciated in Appendix C, detailed fir outputs are not available at the same level of time periodicity as total output, and specifi fir prices are only available for some of the inputs. Therefore, in order to draw our inferences we will use the aggregated and disaggregated versions of the model together.

\footnotetext{
${ }^{12}$ Note that the demand equation is also likely to present some residual autocorrelation, as it is estimated including some explanatory variables, observed only imperfectly (averaged over the interval between reviews).
} 
Firstly, we will use the aggregate model to try to reduce the number of likely outcomes. Recall that this model cannot identify separately behaviour and the regulation constraint, but it can be used advantageously to reject some extreme hypotheses. In practice, this model will allow us to reject the full collusive outcomes. We will therefore rely on the disaggregated model to try to select among the remaining equilibrium concepts. Despite the data limitations, the disaggregated model seems to perform rather well for the models that exclude the appearance of the cross-outputs in the price equations. In fact, finall we will be left with two non-rejected equilibrium concepts.

\section{Econometric results}

In this section, we summarize the main results of our econometric analysis. First, we present the results of a previous separated estimation of the aggregated demand and price equations. Then, we proceed to explain the results of the fully simultaneous estimation of both the aggregated and disaggregated versions of the model. Finally, we describe the testing procedure applied to determine the most likely outcome given the data.

Table 3 presents the results of the separate estimation of the demand and price equations of the aggregated model. The demand equation, estimated by ordinary least squares (OLS), seems a rather good specification All the coefficient have the expected signs, and the resulting equation is not too far from being homogeneous of degree zero in input prices. The equation shows a sensible own price elasticity (2.08), a somewhat stronger elasticity with respect to the price of the compound fertilizers, a near unity elasticity with respect to the price of imports and a high sensitivity to the non-tariff barriers. The peculiar dynamics shown by the price of the compound fertilizers could perhaps be interpreted as a result of a change in the degree of use of this substitute input.

A Hausman test of the exogenity of PNIT in the demand equation, using the cost variables of the price equation as instruments, does not reject it (the same conclusion is obtained when the exogenity of PCOMP is tested). As has been remarked in Section 5, there are some theoretical reasons that can justify this conclusion. In any case, this apparent exogenity may also be the result of a poor instrumentation of the variable and will be repeatedly tested.

The price equation has been estimated by instrumenting the output with the exogenous variables of the demand equation, except PNIT. The signs of the coefficient are as expected, their values are perfectly admissible, and the equality constraints of the separately estimated values of the seasonal dummies (see Appendix B) are accepted in two cases and marginally rejected in two others.

Table 4 presents the joint estimation of the aggregated model by the GMM. We experimented with several estimations, the main difference being the consideration of PNIT as an exogenous or endogenous variable in the demand equation. We 
Table 3

Aggregated model: separate estimation (sample period: 76.01-88.12; $\mathrm{N}^{\mathrm{o}}$ of observations: 144)

\begin{tabular}{|c|c|c|}
\hline Variables and statistics & $\begin{array}{l}\text { Parameters } \\
\text { and values }\end{array}$ & $\begin{array}{l}\text { Standard } \\
\text { errors }\end{array}$ \\
\hline \multicolumn{3}{|c|}{ Demand equation (dependent variable: QNIT) } \\
\hline PNIT & -0.013 & $0.221 \cdot 10^{-2}$ \\
\hline PCOMP* $(-5)$ & 0.014 & $0.263 \cdot 10^{-2}$ \\
\hline PCOMP* $(-1)$ & 0.014 & $0.255 \cdot 10^{-2}$ \\
\hline PIMP $(-1)$ & 1.20 & 0.384 \\
\hline $\operatorname{PSEED}(-7)$ & -0.86 & 0.227 \\
\hline $\mathrm{T}(-2)$ & 14.48 & 2.998 \\
\hline AGOUT & 1.08 & 0.320 \\
\hline AGOUT $(-12)$ & 0.40 & 0.114 \\
\hline QUAL $(-1)$ & -12.14 & 5.053 \\
\hline CLIM $(-1)+(-5)$ & 0.23 & 0.057 \\
\hline Standard error & 25.82 & \\
\hline$R^{2}$ & 0.82 & \\
\hline$Q(12)$-Statistic & 18.39 & \\
\hline \multicolumn{3}{|c|}{ Price equation (dependent variable: PNIT) } \\
\hline QNIT & 19.23 & 2.677 \\
\hline PFUEL & 0.48 & 0.031 \\
\hline PNAPH & 0.076 & 0.025 \\
\hline WAGE & 6.20 & 1.150 \\
\hline $\mathrm{UC}$ & 89.00 & 30.994 \\
\hline Standard error & 1556.80 & \\
\hline$R^{2}$ & 0.96 & \\
\hline$Q(12)$-Statistic & 109.50 & \\
\hline
\end{tabular}

Notes:

1. The demand equation includes a constant and three seasonal dummies $\left(D_{1}, D_{2}\right.$ and $\left.D_{4}\right)$. The price equation includes the complete set of the seasonal dummies $\left(D_{1}\right.$ to $D_{4}$, see Appendix C). Both equations include a small number of dummies which account for some outliers.

2. The variable lags, quoted in brackets, imply a reduction in the number of used observations (from 156 to 144). PCOMP* $(-5)$ is the price of compound fertilizers, lagged fiv months, from the beginning of the sample to December 1985. PCOMP* $(-1)$ is the same price, lagged one month, from January 1986 to the end of the sample. Several tests on the stability of the parameter lead to this specification

3. The demand equation is estimated by OLS. The price equation by IV. The instruments used are the cost variables plus all the explanatory variables in the demand equation with the exception of PNIT. All standard errors are (White) heteroskedasticity robust.

4. An $F$ test for the stability of the coefficient across the two sub-periods 1976.01-1985.12 and 1986.01-1988.12 gives 0.58 . Then, stability is accepted.

5. The $Q(12)$-statistic of the price equation clearly indicates some time autocorrelation of the errors. The re-estimation of this equation with an $\operatorname{MA}(3)$ structure in the errors accounts for this autocorrelation without altering the basic results. 
Table 4

Aggregated model: joint estimation (sample period: 76.01-88.12: $\mathrm{N}^{\mathrm{o}}$ of observations: 144)

\begin{tabular}{|c|c|c|}
\hline Variables and statistics & $\begin{array}{l}\text { Parameters } \\
\text { and values }\end{array}$ & $\begin{array}{l}\text { Standard } \\
\text { errors }\end{array}$ \\
\hline \multicolumn{3}{|c|}{ Demand equation (dependent variable: QNIT) } \\
\hline PNIT & -0.011 & $0.109 \cdot 10^{-2}$ \\
\hline PCOMP * $(-5)$ & 0.014 & $0.141 \cdot 10^{-2}$ \\
\hline PCOMP* $(-1)$ & 0.014 & $0.139 \cdot 10^{-2}$ \\
\hline $\operatorname{PIMP}(-1)$ & 1.10 & 0.185 \\
\hline PSEED $(-7)$ & -0.89 & 0.120 \\
\hline $\mathrm{T}(-2)$ & 14.01 & 2.427 \\
\hline AGOUT & 0.86 & 0.178 \\
\hline AGOUT $(-12)$ & 0.37 & 0.067 \\
\hline QUAL $(-1)$ & -9.09 & 2.789 \\
\hline $\operatorname{CLIM}(-1)+(-5)$ & 0.21 & 0.022 \\
\hline Standard error & 24.74 & \\
\hline$R^{2}$ & 0.81 & \\
\hline \multicolumn{3}{|c|}{ Price equation (dependent variable: PNIT) } \\
\hline QNIT & 16.42 & 2.278 \\
\hline PFUEL & 0.49 & 0.026 \\
\hline PNAPH & 0.080 & 0.015 \\
\hline WAGE & 6.99 & 1.044 \\
\hline $\mathrm{UC}$ & 70.19 & 25.565 \\
\hline Standard error & 1518.48 & \\
\hline$R^{2}$ & 0.96 & \\
\hline Joint statistic: Sargan test & $X^{2}(26)=18.57$ & \\
\hline
\end{tabular}

Notes:

1. See notes 1 and 2 for Table 1.

2. This estimation is carried out by imposing the cross equation constraints on the seasonal dummies.

3. The two equations are jointly estimated by GMM, allowing for time autocorrelation in the errors in the form of a $\operatorname{MA}(6)$. The instruments used in the demand equation are all the variables of this equation. The instruments used in the price equation are the cost variables plus all the explanatory variables in the demand equation with the exception of PNIT. Standard errors are asymptotically robust to heteroskedasticity.

present our preferred estimates, which have been obtained by imposing the theoretical cross-constraints on the seasonal dummies, by allowing for a MA(6) in the disturbances, by considering PNIT to be exogenous in the demand equation, and by using all the variables of this equation (except PNIT), in conjunction with the cost variables, as instruments for the price equation. The Sargan test supports to the validity of the used instruments. The other variants do not alter the basic results.

Table 5 presents the joint estimation of the four equations of the disaggregated model. The poor statistical results achieved in previous estimations with the fully unconstrained general model, together with the behavioural results obtained in the 
Table 5

Disaggregated model: joint estimation (sample period: 76.01-88.12: $\mathrm{N}^{\mathrm{o}}$ of observations: 144$)$

\begin{tabular}{|c|c|c|c|c|c|c|}
\hline $\begin{array}{l}\text { Variables and } \\
\text { statistics }\end{array}$ & $\begin{array}{l}\text { Parameters } \\
\text { and values }\end{array}$ & $\begin{array}{l}\text { Standard } \\
\text { errors }\end{array}$ & & & & \\
\hline \multicolumn{7}{|c|}{ Demand equation (dependent variable: QNIT) } \\
\hline PNIT & -0.014 & $0.135 .10^{-2}$ & & & & \\
\hline PCOMP* $(-5)$ & 0.016 & $0.155 .10^{-2}$ & & & & \\
\hline PCOMP* $(-1)$ & 0.017 & $0.153 .10^{-2}$ & & & & \\
\hline $\operatorname{PIMP}(-1)$ & 1.35 & 0.178 & & & & \\
\hline PSEED $(-7)$ & -0.93 & 0.119 & & & & \\
\hline $\mathrm{T}(-2)$ & 17.67 & 2.529 & & & & \\
\hline AGOUT & 1.02 & 0.150 & & & & \\
\hline AGOUT $(-12)$ & 0.37 & 0.056 & & & & \\
\hline QUAL (-1) & -11.92 & 2.266 & & & & \\
\hline $\operatorname{CLIM}(-1)+(-5)$ & 0.22 & 0.029 & & & & \\
\hline Standard error & 24.92 & & & & & \\
\hline$R^{2}$ & 0.81 & & & & & \\
\hline \multicolumn{7}{|c|}{ Price equations (dependent variable: PNIT) } \\
\hline \multirow[b]{2}{*}{$\begin{array}{l}\text { Variables and } \\
\text { Statistics }\end{array}$} & \multicolumn{2}{|l|}{ ENFERSA } & \multicolumn{2}{|l|}{ ERT } & \multicolumn{2}{|l|}{ CROS } \\
\hline & $\begin{array}{l}\text { Parameters } \\
\text { and values }\end{array}$ & $\begin{array}{l}\text { Standard } \\
\text { errors }\end{array}$ & $\begin{array}{l}\text { Parameters } \\
\text { and values }\end{array}$ & $\begin{array}{l}\text { Standard } \\
\text { errors }\end{array}$ & $\begin{array}{l}\text { Parameters } \\
\text { and values }\end{array}$ & $\begin{array}{l}\text { Standard } \\
\text { errors }\end{array}$ \\
\hline $\mathrm{QNIT}_{i}$ & 16.55 & 0.687 & 48.99 & 1.729 & 54.95 & 2.211 \\
\hline PFUEL & 0.56 & 0.007 & 0.59 & 0.007 & 0.59 & 0.006 \\
\hline PNAPH & 0.138 & 0.007 & 0.147 & 0.007 & 0.118 & 0.006 \\
\hline WAGE $_{i}$ & 2.57 & 0.073 & 2.21 & 0.064 & 3.20 & 0.082 \\
\hline $\mathrm{UC}_{i}$ & 24.21 & 0.878 & 29.06 & 1.301 & 10.63 & 1.050 \\
\hline Standard error & 1558.17 & & 1624.19 & & 1429.58 & \\
\hline$R^{2}$ & 0.96 & & 0.96 & & 0.97 & \\
\hline
\end{tabular}

Notes:

1. See notes 1 and 2 for Table 1 .

2. The four equations are jointly estimated by GMM. The instruments used are the exogeneous variables of the demand equation plus the eight cost variables (the two common variables and the six specifi variables).

aggregated model (see below), lead us to impose a priori the zero constraints on the coefficient of the cross-fir specifi outputs in the price equations. Therefore, the full collusive equilibriums are discarded from the beginning, but the estimated model should be considered a general specificatio compatible with all the remaining outcomes. This is also a GMM estimation, without imposing the theoretical constraints on the dummies and structure in the errors, the set of instruments being common to the four equations. This disaggregated estimation performs rather well, the most remarkable result being the different estimates obtained for the output parameters in the price equations.

Table 6 shows the tests about behaviour and regulation based on the aggregated model. Recall that the output coefficien in the price equation is a function of the 
Table 6

Hypotheses testing: aggregated model

\begin{tabular}{lllc}
\hline Regulation & \multicolumn{3}{l}{ Behaviour } \\
\cline { 2 - 4 } & Market-sharing $(A=1)$ & Cournot $(A=3)$ & Stackelberg $(A=5)$ \\
\hline Non-binding $(\delta=1)$ & 32.21 & 5.76 & 0.47 \\
Binding $(\delta=0.87)$ & 23.06 & 3.55 & -0.74 \\
Binding $(\delta=0.76)$ & 16.88 & 1.85 & -1.70 \\
\hline
\end{tabular}

Notes:

1. $\delta=1$ implies no regulation restriction on the price, $\delta=0.87$ is a naive estimation of the regulation constraint (see footnote 13) and $\delta=0.76$ is the value estimated with the disaggregated model. 1

2. The table reports the results of the tests in the form $\mathrm{H}_{0}: \xi=1-\hat{b} \hat{\gamma} \varphi(A)=0$, where $\varphi(A)=\frac{1}{\delta}[A+$ $(1-\delta)]$ and $\hat{\gamma}$ is the output coefficien obtained in the price equation; $\zeta$ will be distributed as a $t$.

3. The tests are carried out with the parameters estimation obtained in Table $4: \hat{b}=0.011, \operatorname{SE}(\hat{b})=$ $0.001, \hat{\gamma}=16.42$ and $\operatorname{SE}(\hat{\gamma})=2.28$

price parameter in the demand equation, the $\delta$ regulation parameter and the $A$ behavioural parameter. Then, the statistical acceptance of each hypothesis may be tested as the simple acceptance of a non-linear constraint (see Table 6). But, as we have no estimation for $\delta$, its values have to be provided exogenously. In particular, we carried out the test assuming three alternative values for $\delta: \delta=1$, which implies non-binding regulation; $\delta=0.87$, which is the result of interpreting some available data on the firms proposals and the regulator decisions as reflectin the desired prices and the regulator constraints respectively ${ }^{13}$; and $\delta=0.76$, which is the value of $\delta$ we obtain endogenously in our preferred estimation of the disaggregated model (see below). Alternatively, and given our purpose of using this model as a device to restrict the set of possible outcomes, we could have used an arbitrarily small number as the lowest value for $\delta$.

The main result of the tests is that the full collusive behaviour is clearly rejected at the $1 \%$ level under any regulatory hypothesis (non-binding and binding at the two specifie $\delta$ values). The outcome is more ambiguous for Cournot behaviour, that can be rejected at the same level in the non-binding regulation case and the milder binding regulation situation. On the contrary, Stackelberg behaviour can be accepted under both regulatory regimes. Therefore, the aggregate model points clearly to the inconsistency of the most collusive equilibriums with the data, but it is not very conclusive for the remaining outcomes: Stackelberg equilibriums (with and without binding regulation), as well as Cournot under the strongest assumption about the regulation constraint, can be accepted.

\footnotetext{
${ }^{13}$ Suppose that, at every review, the firm proposed a price increase $\Delta_{\tau}^{*}$ that, if accepted, would have pushed the price level to their desired (non-regulated) level. Then, the accepted price increase $\Delta_{\tau}$ would reveal the degree to which regulation constrained the desired price. That is

$$
\delta_{\tau}=\frac{p_{\tau}}{p_{\tau}^{*}}=\frac{p_{\tau-1}\left(1+\Delta_{\tau}\right)}{p_{\tau-1}\left(1+\Delta_{\tau}^{*}\right)}=\frac{1+\Delta_{\tau}}{1+\Delta_{\tau}^{*}}
$$

The scarce information available on proposals and decisions $\left(\Delta_{80}^{*}=0.32, \Delta_{83}^{*}=0.25, \Delta_{84}^{*}=0.33\right.$ and $\Delta_{80}=0.15, \Delta_{83}=0.09, \Delta_{84}=0.19$ ) points to a stable $\delta$ value of about 0.87 . Note, however, that this value is based on the assumption of a rather naive behaviour on the part of the firms
} 
Table 7

Hypotheses testing: disaggregated model

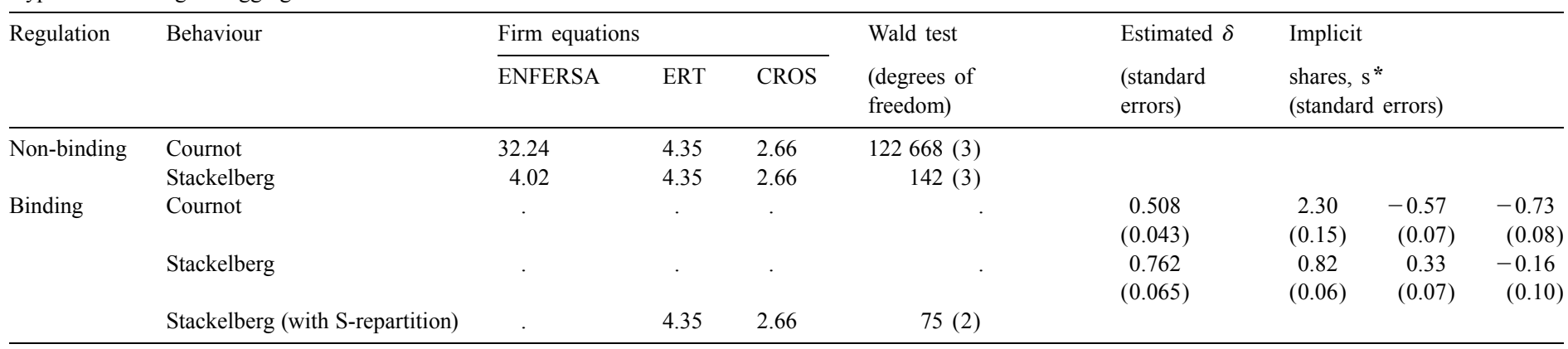

Notes:

1. The firs three columns of the table report the results of the test in the form $\mathrm{H}_{0}: \xi_{i}=1-\hat{b} \hat{\gamma}_{i i} h=0$, where $\hat{\gamma}_{i i}$ is the output coefficien obtained in the price equation of fir $i$, and where $h=3$ for the Stackelberg leader in the Stackelberg model (ENFERSA) and $h=1$ otherwise; $\xi_{i}$ will be distributed as a $t$. The dot means that the corresponding model does not impose a constraint on the output parameter.

2. The fourth column reports the result of a Wald test of the validity of the constraints against the general model.

3. The tests are carried out with the parameters estimation obtained in Table 5: $\hat{b}=0.014, \operatorname{SE}(\hat{b})=0.001, \hat{\gamma}_{11}=16.55, \operatorname{SE}\left(\hat{\gamma}_{11}\right)=0.69, \hat{\gamma}_{22}=48.99, \operatorname{SE}\left(\hat{\gamma}_{22}\right)=1.73, \hat{\gamma}_{33}=$ $54.95, \operatorname{SE}\left(\hat{\gamma}_{33}\right)=2.21$.

4. The last four columns of the table present the results of the direct estimation of the general model in terms of the underlying parameters (entering in a non-linear way). Due to the exact identificatio of the model, the only addition to the estimates of Table 5 are the reported estimated values and standard errors for the $\delta$ parameter and the implicit $\mathrm{s} *$ shares. 
The disaggregated model plays a crucial role here. Remember that from the start we imposed the exclusion cross-output constraints. In this setting, the Cournot and Stackelberg equilibriums under non-binding regulation, and the Stackelberg with S-repartition regulation outcome, can be tested in two ways. First, we can test the cross-equation constraints one by one. Second, we can test the global validity of the constraints of each one of these models against the more general model by means of Wald tests. The results are given in Table 7. The disaggregated version of the model rejects at the $1 \%$ level each one of the previously mentioned outcomes. So, we are left with only two possible results: Cournot and Stackelberg under binding regulation.

To choose between these two models we will rely on the differences that they imply on the estimated structural underlying parameter: $\delta$ and the implicit (estimated) shares. Only the Stackelberg equilibrium shows meaningful values for the shares, although the smallest is statistically indistinguishable from zero. Then, we conclude that the most likely situation given the data was binding regulation, with an estimated $\delta$ parameter of 0.76 , that modifie the Stackelberg equilibrium desired for the firm in the sense of imposing an extra output divided according to the Stackelberg non-binding equilibrium shares.

Given our estimations of the demand function and marginal costs (implicitly estimated in the price equations), it is possible to compute the monopoly solution, the competitive equilibrium, and carry out a welfare analysis. Figs. 6 and 7 show the real price set in the market and the quantities really sold in comparison with the hypothetical prices and quantities corresponding to monopoly and competition. The calculations have been done with the parameter estimates of Table 4, and they can be seen as a sufficien approximation to more accurate feasible calculations.

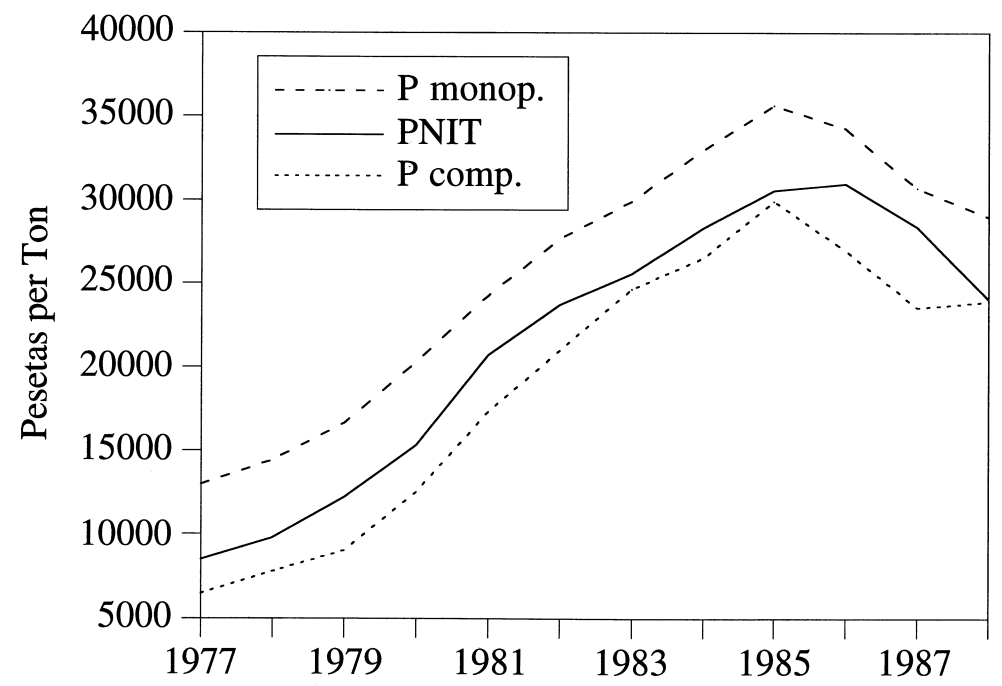

Fig. 6. Prices in monopoly, oligopoly and competition. 


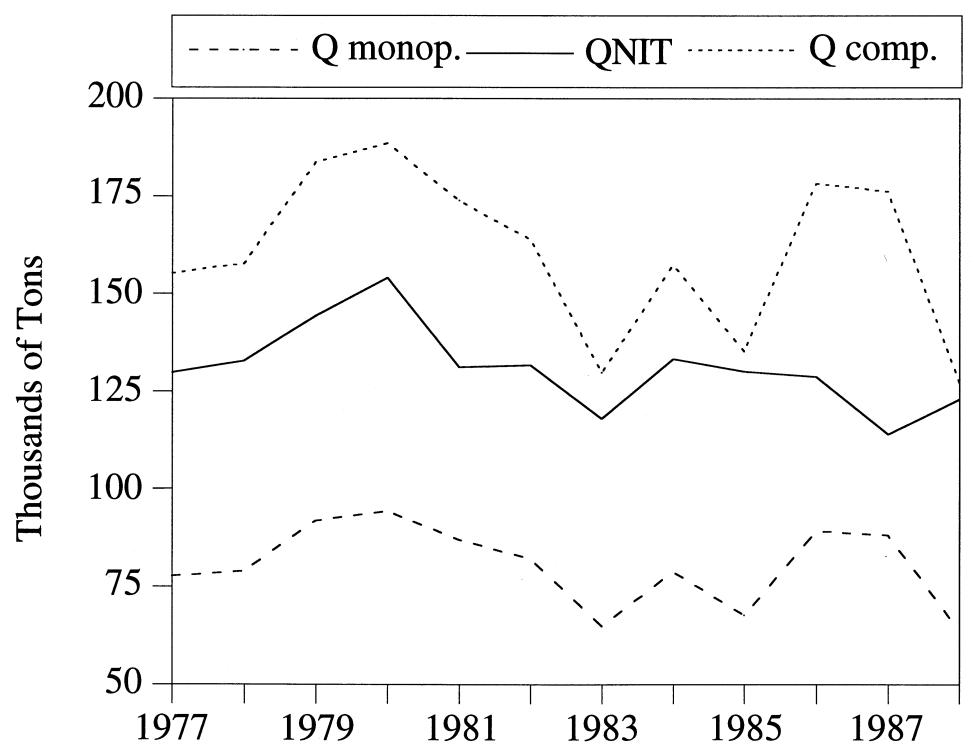

Fig. 7. Output in monopoly, oligopoly and competition.

The implied price-cost margin is, on average, 16 percentage points, the firm are able to capture 27 percent of the consumer surplus, and the deadweight loss is almost 4 percentage points of this surplus. Then, the oligopolistic interaction had noticeable consequences. However the situation was relatively far from the full collusive outcome, which would have implied a 29 percent price-cost margin and a deadweight loss six times greater.

\section{Concluding comments}

The model has been able to select statistically the regulation constrained Stackelberg equilibrium as the most likely outcome in the market, given the observed data. In addition, the welfare analysis carried out with the estimated parameters shows that the price-cost margins, the consumer surplus transferred to the firms and the deadweight welfare loss were noticeable. However, this analysis also shows that regulation was binding and, accordingly, was able to moderate the consequences of market power.

The model is likely to be useful in other price regulation settings and in other contexts in which more informal public supervision may be relevant to induce firm not to price fully according to their desires. In addition, it includes some suggestions as to how to treat empirically nearly collusive outcomes when an agreement in the frontier of profit is not sustainable. 


\section{Acknowledgements}

We are grateful to V. Aguirregabiria, O. Bover, J.C. Fariñas, E. Huerta, I. Macho, M. Maher, J. Segura and the participants at the CEPR/WZB workshop held in Berlin for helpful comments on this work. The comments by two anonymous referees have been very useful. All remaining errors are our own. Financial support from the Ministry of Education project no. PB94-0648-C02-01 is gratefully acknowledged.

\section{Appendix A}

Assume that domestic and imported fertilizers are imperfect substitutes (probably for geographical reasons) with demands, $q=\tilde{q}\left(p, p_{\mathrm{M}}\right)$ and $q_{\mathrm{M}}=q_{\mathrm{M}}\left(p, p_{\mathrm{M}}\right)$, where the $\mathrm{M}$ subscript stands for imports. Under free trade $p_{\mathrm{M}}$ will simply equal $p_{\mathrm{I}}$, where $p_{\mathrm{I}}$ is the price fixe in the imports market by the international producers. In what follows, we will ignore strategic pricing on the part of these producers.

Public authorities intervened in the import market in two ways, firstly by setting tariffs and secondly, by placing obstacles through non-tariff means to the level of imports desired at each international price inclusive of tariffs. The firs intervention simply transforms the relevant price in the above system in $p_{\mathrm{M}}=p_{\mathrm{I}}(1+t), t$ being the tariff. The second raises some difficul questions about how to model the demand for domestic production.

With authorities fixin binding quotas $\bar{q}_{\mathrm{M}}$ on imports, and competition for licenses, $p_{\mathrm{M}}$ would become an endogenous variable according the inverse relationship $p_{\mathrm{M}}=\tilde{p}_{\mathrm{M}}\left(p, \bar{q}_{\mathrm{M}}\right)$, and the relevant demand for the domestic producers would be $q=\tilde{q}\left(p, \tilde{p}_{\mathrm{M}}\left(p, \bar{q}_{\mathrm{M}}\right)\right)=q\left(p, \bar{q}_{\mathrm{M}}\right)$ with $\left(\partial q / \partial \bar{q}_{\mathrm{M}}\right)<0$ (this is, for example, the situation analyzed in Helpman and Krugman (1989), pp. 36-38). But, in our case, there were no publicly stated quotas and competition for licenses was not possible. Instead, only some applications for imports were eventually accepted by the public authority. This situation is probably better characterized as rationing in the imports market, which presumably created positive spillovers on the market for domestic production. In this context, the most sensible specificatio of the demand schedule seems to be $q=q\left(p, p_{\mathrm{M}}, m\right)$, where $m$ stands as an indicator of the rationed demand in the imports market and $(\partial q / \partial \mathrm{m})>0$ is intended to pick-up the spillovers created by the public restrictive intervention.

Empirically, when $p_{\mathrm{M}}$ and the observed imports are included in the demand equation, both of them attract significan rightly signed coefficients This is particularly clear when imports are instrumented to avoid the likely simultaneity bias. We interpret this result as an evidence that neither the free trade nor the pure quotas specificatio are satisfactory. Therefore, given our assessment of the likely situation and the endogenity of imports, we prefer to include the evolution of tariffs as an indicator of the likely parallel evolution of the administrative difficultie to import and hence of the rationed demand. 


\section{Appendix B}

Let us use a double subscript, $t$ denoting the year and $s$ denoting the month. Let $\tau$ denote the moment $t s$ (year and month) in which price is set, and $\emptyset$ the subsequent interval in which the maximum price will remain fixed Assume that the firm expect it to last in total $S$ months. Let us suppose, to simplify things, that firm are identical, that they know with certainty the cost $c_{\tau}$ of producing the next interval, and that they set the perfect collusion price. Then, the problem is simply,

$$
\underset{P \tau}{\operatorname{Max}}\left(p_{\tau}-c_{\tau}\right) \bar{q}_{\tau}^{e}
$$

where $\bar{q}_{\tau}^{e}=\left(\frac{1}{S}\right) \sum_{t s \in \emptyset} E\left(q_{t s}\right)$, and its firs order condition is $q_{\tau}^{e}+\left(p_{\tau}-c_{\tau}\right)\left(\partial \bar{q}_{\tau}^{e} / \partial p_{\tau}\right)=0$. According to the demand specification conveniently simplified the actual output at time $t s$ is given by the equation,

$$
q_{t s}=a_{s}+\alpha z_{t s}-b p_{\tau}+v_{t s}
$$

where $a_{s}$ is the monthly seasonal effect, $z_{t s}$ represents a variable that shifts demand and $v$ stands for a random disturbance of zero mean. Therefore, the expected average output at time $\tau$ for the next relevant interval will be,

$$
\bar{q}_{\tau}^{e}=\frac{1}{S} \sum_{t s \in \varnothing} E\left(q_{t s}\right)=\frac{1}{S} \sum_{t s \in \varnothing} a_{S}+\alpha \frac{1}{S} \sum_{t s \in \varnothing} z_{t s}^{e}-b p_{\tau}=\bar{a}+\alpha z_{\tau}^{\bar{e}}-b p_{\tau}
$$

where $\overline{z_{\tau}^{e}}$ represents the average expectation on variable $z$, and $\bar{a}$ is a constant (provided that an adequate number of months is averaged). From this expression the deviation of the actual output from the expected average output at time $\tau$ will be,

$$
q_{t s}-\bar{q}_{\tau}^{e}=\left(a_{s}-\bar{a}\right)+\alpha\left(z_{t s}-\bar{z}_{\tau}^{e}\right)+v_{t s}=\left(a_{s}-\bar{a}\right)+w_{t s}+v_{t s}
$$

where $w_{t s}$ can present some time autocorrelation, coming from an average forecast error of the variable $z$. Replacing $\bar{q}_{\tau}^{e}$ in the price equation derived from the firs order condition, we obtain the corresponding price equation in terms of the observed variables,

$$
p_{\tau}=\frac{1}{b} \bar{q}_{\tau}^{e}+c_{\tau}=\frac{1}{b} q_{t s}-\frac{1}{b}\left(a_{s}-\bar{a}\right)+c_{\tau}+u_{t s}
$$

where $u_{t s}=-(1 / b)\left(w_{t s}+v_{t s}\right)$. It is easy to check that the reduced form equations for output and price will be,

$$
\begin{aligned}
q_{t s} & =\left(a_{s}-\frac{1}{2} \bar{a}\right)+\frac{\alpha}{2} z_{t s}-\frac{b}{2} c_{\tau}+\frac{1}{2} w_{t s}+v_{t s} \text { and } \\
p_{\tau} & =\frac{1}{2}\left[\left(\frac{\bar{a}}{b}+\frac{\alpha}{b} \overline{z_{\tau}^{e}}\right)+c_{\tau}\right]
\end{aligned}
$$

Several important things can be observed from this example. Firstly, the 
seasonal dummies should also be included in the price equation, and it is possible to constrain them to gain efficienc in two ways: to sum up zero and fulfi a cross-equation equality condition. Secondly, the observed output will be clearly endogenous in the price equation, as is clear from $E\left(q_{t s} u_{t s}\right) \neq 0$. Thirdly, we can expect some time autocorrelation in the error of the price equation, even in the case of a fully specifie demand equation. Fourthly, the price can be exogenous in the demand equation, as $E\left(p_{\tau} v_{t s}\right)=0$ shows.

\section{Appendix C}

\section{Data appendix}

Quantity of nitrogenous fertilizer (QNIT): computed as the consumption of nitrogenous products by Spanish farmers, plus exports less imports. The data are monthly and they are expressed in thousands of tons. In estimation we use the fraction of this quantity sold by the three firms

Quantity of nitrogenous fertilizer sold by fir $i\left(\mathrm{QNIT}_{i}\right)$ : computed as $s_{i} \mathrm{QNIT}$, where $s_{i}$ is the yearly market share of fir $i$.

Price of nitrogenous fertilizers (PNIT): computed as the weighted average of the prices per ton of the different nitrogenous products, using their average shares in demand.

Price of compound fertilizers (PCOMP): computed as the weighted average of the prices per ton of the main compound products (those whose average share was greater than $4 \%$ ).

Price of imports of nitrogenous fertilizers (PIMP): computed by incrementing the Eurostat price index of nitrogenous fertilizers by the amount of the Spanish tariff on imports.

Price of seeds (PSEED): price index with 1976 as the base year.

Tariff (T): prior to 1985, the tariff which obtained in 1985. From the beginning of 1986 onwards, the weighted (demand shares) average of the current tariffs on the different nitrogenous fertilizer products, affected by the progressive reductions established in the Adhesion Agreement with the European Community.

Agricultural output (AGOUT): value of the agricultural output, at constant (1970) prices, in thousands of millions of pesetas.

Average quality of cultivated areas (QUAL): approximated by dividing the agricultural output by the extension in hectares of cultivated area.

Climatology (CLIM): litres of water precipitation per square metre.

Price of fuel (PFUEL): computed by dividing total expenditures in fuel inputs by the quantity used, expressed in thousands of tons.

Price of naphtha (PNAPH): price fixe by government regulation. We use the ceiling price officiall established. 
User cost of capital ( $\mathrm{UC}$ and $\mathrm{UC}_{i}$ ): the aggregate user cost is simply the average of the user costs of the firms To compute the user cost of each fir we proceeded as follows. The nominal specifi interest rate was computed as the ratio of its financia costs to total debt. The rate of depreciation was set at a common value, $8.79 \%$, given by the estimated value of the average life of capital in this industry (11.37 years). As the rate of increase of the price of capital goods, we used the increments of the price index for metallic structures.

Wage (WAGE and $\mathrm{WAGE}_{i}$ ): the aggregated wage is the average labour cost per hour of work in the industry. The specifi wages were computed by dividing each firm' total labour cost by the number of workers.

Seasonal dummies $\left(D_{1}, D_{2}, D_{3}\right.$ and $\left.D_{4}\right): D_{1}=$ January + February + March + November; $\quad D_{2}=$ April + September + October; $\quad D_{3}=$ May + June + July + August; $D_{4}=$ December.

For some variables (AGOUT, QUAL, PFUEL, UC and WAGE) the data were on a yearly basis. Their yearly value was then adopted in our estimations for every month of the year in question.

Data sources were several publications of the Ministry of Agriculture, the Spanish Industrial Survey and the firms balance sheets.

Variable statistics (1976.01-1988.12)

\begin{tabular}{lrr} 
& \multicolumn{1}{c}{ Mean } & Standard deviation \\
QNIT $_{\text {QNIT }_{\text {ENF }}}$ & 127.85 & 56.75 \\
QNIT $_{\text {ERT }}$ & 76.74 & 34.18 \\
QNIT $_{\text {CROS }}$ & 32.55 & 14.57 \\
PNIT & 18.56 & 9.01 \\
PCOMP & 20466.78 & 8350.47 \\
PIMP & 22462.86 & 8265.81 \\
PSEED & 118.10 & 25.47 \\
T & 220.59 & 86.83 \\
AGOUT & 10.58 & 1.25 \\
QUAL & 361.61 & 44.85 \\
CLIM & 22.99 & 2.55 \\
PFUEL & 53.55 & 35.10 \\
PNAPH & 17275.90 & 8883.13 \\
UC & 19126.30 & 10490.65 \\
UC $_{\text {ENF }}$ & 29.59 & 18.95 \\
UC $_{\text {ERT }}$ & 29.79 & 19.02 \\
UC $_{\text {CROS }}$ & 25.78 & 16.67 \\
WAGE $_{\text {WAGE }}$ & 33.20 & 23.42 \\
WAGE $_{\text {ERT }}$ & 843.51 & 390.74 \\
WAGE $_{\text {CROS }}$ & 2193.91 & 970.42 \\
& 2065.54 & 1071.30 \\
& 1922.43 & 875.24
\end{tabular}




\section{References}

Berheim, B.D., Whiston, M.D., 1990. Multimarket contact and collusive behaviour. Rand Journal of Economics 21, 1-16.

Berndt, E., A.F. Friedlaender and J.S.W. Chiang, 1990, Interdependent pricing and markup behaviour: an empirical analysis of GM, Ford and Chrysler, National Bureau of Economic Research Working Paper Series 3396, June.

Bresnahan, T.F., 1989, Empirical studies of industries with market power, in: R. Schmalensee and R.D. Willig, eds., Handbook of Industrial Organization, Vol. II (North-Holland) 1011-1055.

Bulow, J.I., Geanakoplos, J.D., Kemplerer, P.D., 1985. Multimarket oligopoly: strategic substitutes and complements. Journal of Political Economy 93, 488-511.

Burrell, A., 1989. The demand for fertilizer in the United Kingdom. Journal of Agricultural Economics 40 (1), 1-20.

Daughety, A.F., 1984. Regulation and industrial organization. Journal of Political Economy 92, 932-953.

Dixit, A., 1979. A model of duopoly suggesting a theory of entry barriers. Bell Journal of Economics $10,20-32$.

Dixit, A., 1980. The role of investment in entry deterrence. Economic Journal 90, 95-106.

Fudemberg, D. and J. Tirole, 1993, Game Theory (MIT Press).

Gasmi, F., Laffont, J.J., Vuong, Q.H., 1992. Econometric analysis of collusive behavior in a soft-drink market. Journal of Economics and Management Strategy 1, 277-311.

Hansen, L.P., 1982. Large sample properties of generalized method of moments estimators. Econometrica 50, 1029-1054.

Hansen, L.P., Singleton, K.L., 1982. Generalized instrumental variables estimation of nonlinear rational expectations models. Econometrica 50, 1269-1286.

Helpman, E. and P.R. Krugman, 1989, Trade Policy and Market Structure (MIT Press).

Kreps, D., Scheinkman, J., 1983. Quantity precommitment and Bertrand competition yield Cournot outcomes. Bell Journal of Economics 14, 326-337.

Laffont, J.J. and J. Tirole, 1993, A Theory of Incentives in Procurement and Regulation (MIT Press).

MINER, 1985, Plan de reconversión para el sector de fertilizantes (Ministerio de Industria y Energí a, Madrid).

Ogaki, M., 1993, Generalized method of moments: econometric applications, in: G.S. Maddala, C.R. Rao and H.D. Vinod, eds., Handbook of Statistics, vol. II (Elsevier Science) 455-488.

Pazo Martinez, M.C., 1994, Modelas empí ricas de oligopolio: una aplicacion en un mercado regulado, Ph.D., unpublished.

Phlips, L., 1983, The economics of price discrimination (Cambridge University Press).

Rotemberg, J., Saloner, G., 1986. A supergame-theoretic model of business cycles and price wars during booms. American Economic Review 76, 390-407.

Schmalensee, R., 1987. Competitive advantage and collusive optima. International Journal of Industrial Organization 5, 351-367.

Tirole, J., 1988, The Theory of Industrial Organization (MIT Press). 